\title{
El lugar social de la teología*
}

\author{
Francisco de Aquino Júnior, \\ Facultad Católica de Fortaleza
}

En otra ocasión, abordamos la problemática del carácter social de la teología ${ }^{1}$, mostrando en qué sentido toda teología es social, es decir, que trata de una realidad que tiene una dimensión social, que es un quehacer socialmente interesado, eclesialmente situado y condicionado, posibilitado por estructuras de pensamiento y por sistemas de conceptos socialmente desenvueltos y mediados e inseridos en la compleja trama de los conflictos sociales. En esa ocasión, concluíamos con aportes con vistas a la necesidad de dar un paso adelante en la reflexión determinando, teórica y teológicamente, el lugar social de la teología. No basta reconocer que toda teología es social, consciente o inconscientemente. Es necesario asumir de manera consciente y consecuente ese carácter social, metiéndose en la complejidad y ambigüedad de los conflictos sociales y determinando el lugar social más adecuado y fecundo para el propio quehacer teológico.

Teniendo como presupuesto todo lo que escribimos sobre el carácter social de la teología, nos confrontaremos aquí con la problemática de la determinación del lugar social de la teología. Son dos aspectos del mismo problema. Ambos dicen respecto a lo social de la teología. No obstante, en cuanto el primer aspecto tiene un carácter más formal y abstracto y, en principio, parece menos problemático (insiste en el carácter social de la teología), el segundo aspecto tiene un carácter más concreto y empírico y, por eso, toca más directamente los conflictos y provoca mucha más reacción (determina el lugar social de la teología). Sin el primer aspecto, el segundo carece de fundamento; y sin el segundo aspecto, el primero es fácilmente ideologizado bajo la apariencia de universalidad y cientificidad. De ahí la necesidad de avanzar en la reflexión, pasando de la mera explicitación del carácter social de la teología a la determinación de su lugar social. Es el objetivo de este trabajo.

* Traducción al español de Aníbal Atalibal Lorca, S.J.

1. Cf. F. Aquino Júnior, "El carácter social de la teología", Revista Latinoamericana de Teología 90 (2013), pp. 279-298. 
Comenzaremos explicitando en qué sentido hablamos de lugar social (1), para confrontarnos, en seguida, con el problema del lugar social de la teología (2) y, finalmente, con la determinación del lugar social de la teología (3).

\section{Lugar social}

Antes de todo, es necesario determinar con cierto rigor lo que entendemos por lugar social. Aunque se trate de una expresión bastante común en el ámbito de las ciencias sociales, en ciertas corrientes o tradiciones teológicas - concretamente, en las diversas teologías de la liberación-, y de modo cada vez más creciente en las diversas ciencias, su sentido es poco preciso, sobre todo si se trata del proceso de conocimiento. Y lo curioso es que esta expresión es usada comúnmente como si fuese algo claro, evidente, que dispensase de aclaraciones. Tanto que no es nada fácil encontrar una definición precisa y rigurosa del concepto de lugar social.

Esto puede ser ya un indicio de la verdadera dificultad de tal definición, una vez que se trata aquí de una expresión equívoca, polisémica, analógica, particularmente en lo que se refiere al concepto lugar. Este puede indicar tanto un espacio físico-geográfico como una posición o situación social, o también un punto de vista intelectivo. Y los tres sentidos tienen que ver con lo social, tienen algo de social. De modo que la expresión lugar social puede ser tomada en alguno de esos diferentes sentidos. Dependiendo del enfoque o del énfasis que se dé al concepto lugar, la expresión tendrá un sentido u otro, o, en todo caso, un acento u otro. Conviene, por eso, explicitar esos diferentes sentidos, tanto en lo que tienen de específico como en lo que tienen de común. Solo así podremos definir con cierto rigor la expresión lugar social y, de esa forma, identificar y comprender la realidad a la cual hace referencia y busca explicitar.

a. La expresión lugar social indica, antes que todo, un espacio físico-geográfico: el dónde físico, real, concreto, material en que se está. Este es su sentido más básico y primario. Tiene que ver con la materialidad fundamental y constitutiva de la vida humana. Siempre se está en un lugar físico-material: casa-calle, campo-ciudad, centro-periferia, barrio-urbanización, vertedero de basuraempresa, capital-interior, Europa/EE. UU.-América Latina/África, norte-sur y así en adelante. No hay escapatoria.

Pero ese lugar físico-material donde se está no es simplemente un lugar natural. Es un lugar ocupado y organizado socialmente y, por eso, en sentido estricto, un lugar social. La propia designación de ese lugar físico-material (casacalle, vertedero de basura-empresa, Europa-África, etc.) revela su carácter social: ocupación y organización social del espacio natural. En la medida en que es ocupado y organizado por el ser humano, el espacio deja de ser algo meramente natural; es inserido en la trama compleja y conflictiva de las relaciones sociales, convirtiéndose, así, en una realidad social o, en todo caso, una realidad social- 
mente organizada y configurada. No es casualidad que la llamada geografía humana o social haya hablado de "espacio geográfico" o "espacio social" (Milton Santos) $)^{2}$, de "territorio" (Claude Raffestin) ${ }^{3}$, destacando con eso la interacción natural-social, particularmente en lo que dice respecto al modo de producción, a la organización y configuración del espacio geográfico ${ }^{4}$. La ciudad ${ }^{5}$ como un todo y, en ella, la arquitectura es un buen ejemplo del carácter social del espacio físico. La localización, el tamaño y el tipo de una construcción cualquiera, vista y analizada en el conjunto arquitectónico de una ciudad, expresa/revela el poder adquisitivo de sus propietarios y las relaciones de poder en esa sociedad. Eso se puede constatar hasta en los cementerios ${ }^{6}$. Basta comparar los diferentes camposantos y, en cada uno, las diferentes tumbas o panteones para notar que la apropiación y la organización del espacio físico es un dato social, determinado por relaciones desiguales de poder en una sociedad concreta.

De manera que, en cuanto espacio físico-geográfico, lugar social designa, por un lado, la organización social de un determinado espacio, y, por otro lado, las relaciones de poder que se establecen en la organización social de ese espacio y que determina su apropiación y, consecuentemente, su organización y configuración. El dónde físico-material en que se está no es, por tanto, un mero dato natural. Es una construcción/determinación social, fruto de relaciones sociales conflictivas y desiguales que nos obligan a hablar no solo de lugar social en singular, sino de lugares sociales en plural. Ya, aquí, en el sentido más básico y fundamental de la expresión, se revela su carácter plural y conflictivo. En la sociedad hay muchos lugares y estar en un lugar u otro no es un dato natural, sino una determinación social.

b. La expresión lugar social indica también posición o situación social en el conjunto de la sociedad. Además de estar en un lugar físico-material, las personas, en sus relaciones personales y estructurales, se encuentran siempre en una situación social y ocupan siempre una posición social bien concreta.

2. Cf. M. Santos, A natureza do espaço: técnica e tempo, razão e emoção, São Paulo: Edusp, 2004; y Da totalidade ao lugar, São Paulo: Edusp, 2005.

3. Cf. C. Raffestin, Por uma geografia do poder, São Paulo: Ática, 1993.

4. Para el caso concreto de la organización y configuración del espacio geográfico cearense, $c f$. D. Elias y J. L. Sampaio, Modernização excludente: paradigmas da agricultura cearense, Fortaleza: Demócrito Rocha, 2002; L. C. Lima, T. S. Vasconcelos y B. M. Freitas, Os novos espaços seletivos no campo, Fortaleza: UECE, 2011.

5. A propósito de la ciudad de Fortaleza, por ejemplo, $c f$. J. B. Silva, Os incomodados não se retiram, Fortaleza: Fundação Demócrito Rocha, 1992; Nas trilhas da cidade, Fortaleza: Museu do Ceará, 2005.

6. Cf. H. S. Batista, Assim na Morte como na Vida: Arte e sociedade no cemitério São João Batista (1866-1915), Fortaleza: Museu do Ceará, 2012. 
Situación o posición que dice respecto al acceso a los bienes y riquezas, a las relaciones de poder, al servicio o profesión, al saber, al color de la piel, a la etnia, a la orientación/opción sexual, etc.

Dependiendo de la situación social o la posición social en que alguien se encuentra (pobre-rico, patrón-empleado, recolector de basura-empresario, doctor-analfabeta, blanco-negro, indio-europeo, hombre-mujer, homosexualheterosexual, etc.), ocupará un lugar social u otro. De modo que el lugar social tiene una dupla característica: es fruto de las relaciones de poder y de relaciones de poder extremadamente desiguales que llevan a la dominación de unos sobre otros. Por un lado, es fruto de las relaciones de poder que se establecen en el proceso de organización y configuración de la vida colectiva. Que alguien sea rico o pobre, que determinada profesión tenga mayor o menor estatus, que el color de la piel o la orientación sexual definan el lugar o la posición que alguien ocupa en una sociedad, por ejemplo, no es un dato natural, sino un dato social, resultado del proceso de organización y configuración de la vida colectiva. Por otro lado, revela el carácter desigual de las relaciones de poder en ese proceso de organización y configuración de la vida colectiva, lo que lleva a la construcción de una sociedad extremadamente desigual, fundada y regulada a partir y en vista de la dominación de unos sobre otros. Es aquí donde se da el proceso desigual de apropiación y/o distribución de bienes y riquezas (ricos-pobres). Es aquí donde las diferencias (indio-europeo, hombre-mujer, homosexual-heterosexual, etc.) se vuelven escenario de dominación. Y es aquí donde se construyen discursosteorías-valores que fundamentan y legitiman esa situación (ideologías mitológicas, filosóficas, teológicas y científicas, lenguaje, etc.)": "reconozca su lugar", "póngase en su lugar", etc.

En cuanto posición que alguien ocupa o situación en que alguien se encuentra en una determinada sociedad, el lugar social se constituye, por tanto, en una determinación o construcción social. No es un dato natural, no es un destinocasualidad ni mucho menos la decisión de unos dioses o fuerzas del más allá. Es un dato social, fruto de relaciones de poder desiguales que llevan a la organización y configuración de la sociedad a partir y en vista de la dominación de unos sobre otros. De modo que también, y especialmente aquí, es preciso hablar de lugares sociales en plural y de lugares sociales no solo diferentes, sino asimétricos y en conflicto. Hay, por tanto, diferentes lugares en la sociedad. Y esa diferencia se constituye y caracteriza como desigualdad, como explotación, como dominación, como subordinación.

7. Cf. M. Chaui, O que é ideologia, São Paulo: Brasiliense, 1997; P. Freire, Pedagogia da autonomia: saberes necessários à prática educativa, São Paulo: Paz e Terra, 1997, pp. 141-152. 
c. Finalmente, lugar social designa punto de vista intelectivo: "Todo punto de vista es la vista a partir de un punto". También el acceso que tenemos a las cosas y a los acontecimientos (visión, aprehensión), el modo como los inteligimos (sentido, praxis, prejuicios, etc.) y la perspectiva a partir de la cual y en función de la cual los inteligimos (intereses inherentes a la praxis) son, en buena medida (¡mucho más de lo que se piensa!), condicionados y realmente determinados por el lugar en que nos encontramos.

El proceso de intelección ${ }^{8}$ no es algo que se da independientemente de la vida concreta de las personas. Es un momento del proceso de enfrentamiento de las personas con el mundo o con las cosas, esto es, de la praxis humana. Y como la praxis humana es una praxis situada, la inteligencia, como momento de la praxis, solo puede ser una actividad situada: en un determinado espacio físico-geográfico y en una determinada posición o situación social. De una forma o de otra, la intelección humana está condicionada y posibilitada por el lugar social en que nos encontramos. No es lo mismo estar en un lugar social o en otro. Sea porque no siempre se tiene acceso a las mismas realidades en los diferentes lugares sociales (facultad de medicina, tecnología de punta, turismo, etc.). Sea porque una misma realidad puede ser abordada desde diferentes perspectivas (física, biológica, sociológica, económica, teológica, etc.) y a partir de intereses diferentes o contrarios (sin tierra-latifundista, recolector de basura-empresario, etc.). Sea, en fin, porque las estructuras de pensamiento y los sistemas de conceptos socialmente producidos y mediados son distintos y quizá contrarios en diferentes lugares sociales (oriente-occidente, rural-urbano, cultura patriarcalmovimiento feminista, etc.), por más que las fronteras entre esos lugares no sean siempre tan obvias. Así, por ejemplo, un basurero puede ser visto y analizado desde perspectivas e intereses diferentes (colectores para reciclar, empresarios, gestores públicos, sociólogos, agentes de pastoral, teólogos, etc.); la entrada de un grupo de personas sin tierra en una propiedad puede ser vista y analizada desde intereses contrarios ( (ocupación-invasión).

Es importante, en todo caso, percibir que la intelección humana es una actividad socialmente condicionada y posibilitada, y que, por eso mismo, no es indiferente para el proceso de intelección el lugar social en que se esté. Y eso vale no solo para el llamado sentido común, sino también para el conocimiento científico, a pesar de la pretensión ingenua e ideológica de neutralidad social de algunos "científicos". Bastaría ver el direccionamiento social de una actividad técnico-científica cualquiera (a quién se dirige; a qué modo de producción y a

8. Para una visión global y sintética del proceso de intelección en la perspectiva de Xavier Zubiri e Ignacio Ellacuría, $c f$. F. Aquino Júnior, A teologia como intelecção do reinado de Deus: o método da teologia da libertação segundo Ignacio Ellacuría, São Paulo: Loyola, 2010, pp. 215-245. 
qué modelo de sociedad favorece; quién se beneficia de ella) para saber que su neutralidad social, enmascarada de objetividad y cientificidad, no es tan neutral ${ }^{9}$.

En síntesis, lugar social puede designar tanto espacio físico-geográfico como posición o lugar social, como, también, punto de vista intelectivo. Este se refiere al "dónde" físico, social, intelectivo se está y a partir de dónde se actúa. Un "dónde" socialmente determinado. Y determinado en proceso de organización y configuración de la vida colectiva, mediante relaciones de poder extremadamente desiguales. De ahí que no sea suficiente hablar de lugar social en singular, ni siquiera de lugares sociales en plural, puesto que no se trata simplemente de lugares sociales diferentes. En nuestra sociedad, esa diferencia se configura como desigualdad, opresión, dominación, subordinación. Por eso, es necesario hablar con todo rigor y sin escrúpulo de lugares sociales desiguales y conflictivos, por más que nuestra vida colectiva y los lugares sociales en que estamos no puedan ser reducidos a lo que tiene de desigualdad y de conflicto.

Finalmente, conviene alertar contra simplificaciones maniqueístas y deterministas en lo que se refiere a la ocupación de los diferentes lugares sociales en una sociedad concreta. La cuestión es más compleja de lo que parece: hay pobres en el Primer Mundo y en urbanizaciones de cualquier gran ciudad, y hay ricos en el Tercer Mundo y hasta en el barrio de la periferia; hay pobres que se oponen a la lucha de los sin tierra y de los sin casa, y hay personas de clase media que defienden y apoyan esta lucha; hay mujeres machistas, negros racistas, homosexuales homofóbicos y hay hombres, blancos y heterosexuales que no solo viven relaciones igualitarias de género y de respeto y compañerismo con mujeres, negros y homosexuales, sino, incluso, que asumen sus causas; y así sucesivamente. Sin embargo, es necesario tener cuidado de no tomar la excepción como regla y de no confundir el lugar en que realmente se está como el lugar que se asume explícita y conscientemente por realismo y/o por compromiso. En definitiva, el hecho de que un pobre esté contra la lucha de otro pobre o tenga cabeza de rico (defienda los intereses de los ricos) no lo hace dejar su condición de pobre ni lo convierte en rico — no cambia su lugar social-; el hecho de que

9. "Las ideas de autonomía de la ciencia y del desinterés del conocimiento científico, que durante mucho tiempo constituyeron la ideología espontánea de los científicos, colapsó frente al fenómeno global de la industrialización de la ciencia a partir, sobre todo, de las décadas de los treinta y cuarenta. Tanto en las sociedades capitalistas como en las socialistas de Estado en el Este de Europa, la industrialización de la ciencia acarreó con el compromiso de esta con los centros de poder económico, social y político, los cuales pasaron a tener un papel decisivo en la definición de las prioridades científicas" (B. S. Santos, Um discurso sobre as ciências. São Paulo: Cortez, 2010, pp. 56 y s.). Para un abordaje más amplio y profundo de la problemática, $c f$. B. S. Santos (comp.), Conhecimento prudente para uma vida decente: 'um discurso sobre as ciências' revisitado, São Paulo: Cortez, 2006. 
una mujer sea machista, de que un negro sea racista, de que un homosexual ser homofóbico no solo no cambia su lugar social inferior y subordinado, sino que contribuye para que este se mantenga y se profundice. De la misma forma, el hecho de que una persona de clase media asuma y defienda la causa de los pobres o el hecho de que un hombre, un blanco y un heterosexual asuman y defiendan la causa de las mujeres, de los negros y de los homosexuales no cambia su lugar social. La diferencia, aquí, es que contribuye en el proceso de transformación de la sociedad a partir y en vista de las relaciones fraternas e igualitarias. Tener presente esa complejidad del lugar social, sobre todo en lo que se refiere a la diferencia entre el lugar en que realmente se está y el lugar que se asume, es muy importante tanto para evitar maniqueísmos simplistas como para evitar universalismos ingenuos y/o ideológicos.

Es importante, en todo caso, tener presente las siguientes cuestiones: (1) en nuestra sociedad, hay diferentes lugares sociales; (2) esa diferencia se configura como desigualdad, dominación, subordinación; (3) estar en un lugar u otro condiciona enormemente tanto la acción humana en general como su intelección de las cosas y de los acontecimientos; (4) no siempre el lugar en el que realmente se está coincide con el lugar que se asume explícita y conscientemente, por realismo o por opción; (5) asumir un lugar diferente al lugar en el que realmente se está no significa un cambio real, sino, dependiendo del lugar asumido, contribuye para mantener o para transformar las estructuras sociales desiguales y dominadoras; (6) en la medida en que los lugares sociales son determinados en el proceso de organización y configuración de la vida colectiva, por tanto, en un proceso social, son mantenidos o transformados en el mismo proceso social, mediante alteraciones en la correlación de fuerzas; y (7) aquí se revela la importancia y la necesidad de los movimientos sociales en el proceso de transformación de la sociedad, a partir y en vista de relaciones sociales fraternas e igualitarias.

\section{La problemática del lugar social de la teología}

Después de explicitar lo que entendemos por lugar social, vamos a confrontarnos ahora con la problemática del lugar social de la teología. ¿Tiene sentido hablar del lugar social de la teología en cuanto teoría? ¿No sería eso una mera ideologización de la teología en detrimento de su calidad y rigor teórico-científico? ¿Valdría eso para toda y cualquier teología o solo para las relacionadas con organizaciones y movimientos sociales (de izquierda) y que, a fin de cuentas, más que de teología propiamente dicha, se trataría de un discurso político-ideológico disfrazado de religioso, bien o mal intencionado? ¿No sería la teología, en cuanto ciencia, un discurso objetivo y universal, y por tanto, socialmente neutro, por encima de los intereses y conflictos sociales? Sobre todo, tratándose de los pronunciamientos del magisterio eclesiástico, especialmente en sus definiciones dogmáticas, ¿se podría continuar hablando de lugar social? ¿No comprometería esto y/o negaría su destino y validez universal? En última instancia ¿no llevaría 
eso a un relativismo radical que terminaría negando no solo el conocimiento total de la verdad (siempre limitado y relativo), sino la posibilidad de acceso a la verdad o, quién sabe, la propia verdad?

Todo esto apunta a la complejidad de la problemática del lugar social de la teología. Aun aceptando que la comunidad eclesial, en cuanto organización y fuerza social, está inserida en la compleja y conflictiva trama de relaciones sociales y que, por tanto, está siempre -queriendo o sin querer, consciente o inconscientemente - en un lugar social determinado, permanece abierta la problemática del lugar social de la teología. Pues podría ocurrir que la teología, en cuanto ciencia, tuviese un dinamismo no solo distinto, sino completamente diferente e independiente del dinamismo de la vida y de la praxis eclesial. De modo que, incluso admitiéndose que la praxis eclesial sea una praxis socialmente condicionada y mediada, se podría continuar pensando que la teología, en tanto actividad teórica, no está necesariamente condicionada y determinada por el lugar social. Por más que se pueda y hasta se deba establecer alguna relación entre lugar social y quehacer teórico, sería siempre relación entre relatos ya constituidos y, por ende, un vínculo meramente externo y secundario ${ }^{10}$. Ahora bien, esto es muy simple.

La problemática del lugar social de la teología surge con

la sospecha de que el lugar desde donde se interpreta y se realiza algo es fundamental para el resultado de la interpretación y de la realización, y de que esa fundamentalidad no es inmediatamente percibida como tal, de suerte que, sin caer en la cuenta, esto es, de forma más o menos "inconsciente", se están poniendo en el objeto del estudio o de la praxis los intereses no confesados que responden a la instalación en un lugar determinado. Si esto es así, en toda interpretación y realización de alguna importancia vital, lo es de modo singular en la interpretación de la fe y en su praxis que tan de lleno toca a la totalidad de la vida y a sus intereses más profundos. Y esto es válido tanto para los individuos como para el grupo social, aunque el mecanismo y los efectos sean diversos en un caso y en el otro."

10. Por ahí parece ir la postura de Clodovis Boff con su separación y contraposición entre vida/praxis y pensamiento/teoría y con su visión althusseriana de la "práctica teórica" ( $c f$. C. Boff, Teologia e prática: teologia do político e suas mediações, Petrópolis: Vozes, 1993, pp. 144-158; Teoria do método teológico, Petrópolis: Vozes, 1998, pp. 56 y s, 110-113, 117, 121, 168, 391). En esta perspectiva llega, a lo máximo, a proponer una "relación" entre "lugar social" y "lugar epistémico", formulada, con M. de Certeau, en los términos de "permiso" y "defensa" ( $c f$. C. Boff, Teologia e prática, op. cit., pp. 290-296).

11. I. Ellacuría, "La Iglesia que nace del pueblo por el Espíritu", en Escritos teológicos, t. II, San Salvador: UCA Editores, 2000, pp. 343-355, aquí 344. 
Cuatro puntos merecen ser destacados.

a. No solo la acción eclesial es una acción socialmente situada. También la acción intelectual o más precisamente el momento intelectivo de la acción está socialmente situado. Se da siempre a partir y en referencia a un determinado lugar social que lo condiciona tanto negativamente como lo posibilita positivamente. Como bien afirma Ignacio Ellacuría, “el 'desde dónde' en el cual se sitúa uno al querer ver, es decisivo para lo que se puede alcanzar ver; el horizonte y la luz que se selecciona son también fundamentales para lo que se va a ver y el modo como se va a ver"12. O, más aún, "los condicionamientos de los lugares en que uno se sitúa para encontrar respuestas a los problemas teóricos y prácticos son de gran importancia tanto para favorecer como dificultar ese encuentro"13. De modo que el lugar social tiene una importancia fundamental para el "resultado" de la acción y, en concreto, de su momento más propiamente intelectivo.

b. Esa importancia fundamental del lugar social tanto para la "realización" como para la "interpretación" no es algo inmediatamente percibido ni necesariamente asumido de modo consciente y consecuente. Hasta porque el fundamento o lo fundamental, por su propia naturaleza, está por debajo de lo que se ve - sustentándolo - y normalmente no se muestra ni se deja percibir con facilidad. Eso lo hace aún más problemático y desafiante, pues va condicionando y determinando la acción y su momento intelectivo por intereses no confesados ni asumidos de modo explícito y consciente. Y lo que es peor, en la mayoría de las veces, disfrazados y enmascarados ideológicamente de universalidad, objetividad, cientificidad, es decir, la verdad sin más. Basta ver con más atención las teorías y los discursos sobre los desarrollos "técnicos", patriarcales, racistas, etnocéntricos, homofóbicos, centralistas, entre otros, para identificar su lugar social.

c. Lo que vale para la praxis y para su momento intelectivo, en general, vale, de modo particular, para la praxis eclesial, y sobre todo, para la teología ${ }^{14}$. Primero, por tratar de cuestiones que se refieren a la orientación y al sentido más profundo y definitivo de la vida humana (el hacia dónde y por qué). Eso no es indiferente a los intereses y conflictos sociales. Segundo, porque toca aspectos mucho más propensos a "desfiguraciones y manipulaciones no siempre conscientes", dado el

12. I. Ellacuría, "Historicidad de la salvación cristiana", en Escritos teológicos, t. I, San Salvador: UCA Editores, 2000, pp. 535-596, aquí 592.

13. I. Ellacuría, "Hacer la paz en El Salvador", en Escritos políticos, t. II, San Salvador: UCA Editores, 1993, pp. 1139-1150, aquí 1149.

14. $C f$. B. Ferraro, "A teologia como produto social e produtora da sociedade: a relevância da teologia", en P. A. Baptista y W. L. Sánchez, Teologia e sociedade: relações, dimensões e valores éticos, São Paulo: Paulinas, 2001, pp. 43-56. 
carácter "aparentemente" inverificable de muchas de sus afirmaciones ${ }^{15}$. El hecho es que

las afirmaciones más abstractas pueden resultar a veces la expresión religiosa de una situación, cuya verdad es todo menos religiosa. El discurso religioso puede ser una mistificación del discurso económico y político y esto no solo cuando fetichiza realidades históricas determinadas [...] sino incluso cuando aparentemente no habla más que de Dios y de lo divino. Sin llegar a la exageración de pensar que todo discurso teológico es solamente esto, cabe siempre la pregunta y la sospecha de cuánto de esto hay en todo discurso teológico. ${ }^{16}$

d. El condicionamiento de la teología por el lugar social tiene que ver no solo con la teología producida por un determinado teólogo, sino también con la teología bíblica ${ }^{17}$ y la teología producida por el magisterio de la Iglesia, inclusive, en sus definiciones y formulaciones dogmáticas ${ }^{18}$. La apelación a la revelación, al magisterio y al carácter dogmático de sus definiciones no niega, en ninguna hipótesis, su condicionamiento social. Primero, porque la revelación se da en la historia e históricamente, por tanto, en la compleja y conflictiva trama de los intereses y conflictos sociales. Segundo, porque los obispos, así como los teólogos, no están por encima de la historia y los conflictos sociales. Tercero, porque las propias definiciones dogmáticas (en su necesidad y su formulación) solo pueden

15. I. Ellacuría, "La teología como momento ideológico de la praxis eclesial", en Escritos teológicos, t. I, op. cit., pp. 163-185, aquí 165.

16. Ibid., p. 166.

17. Cf. N. Gottwald, As Tribos de Iahweh: uma sociologia da religião de Israel liberto 1250-1050 a.C., São Paulo: Paulinas, 1986, pp. 701-710. "El surgimiento de Israel manifestó la asociación entre la tentativa de introducir un cambio en las relaciones sociales en una determinada etapa del nivel alto del proceso de evolución social, en el antiguo Oriente Próximo, y la tentativa de introducir un cambio en la percepción y práctica religiosa, en una determinada etapa del nivel más alto de la revolución religiosa en el antiguo Oriente Próximo [...]. Una experiencia social radical generó una teología radical, sin la cual no podría haber tenido un éxito completo como lo tuvo. Si el simbolismo de Iahweh era esencial a la emergencia de Israel, no se debe pasar por alto (como en general pasan los teólogos bíblicos) el hecho de que la religión javista fue la praxis y la ideología de una comunidad social verdadera. El foco de todo aquel simbolismo religioso súper desarrollado eran las relaciones sociales de un pueblo" (ibid., p. 701). "Si mi línea de raciocinio respecto a la relación de la teología bíblica y la sociología bíblica fuera correcta, la contribución más importante de un análisis sociológico del primitivo Israel para el pensamiento y las prácticas religiosas contemporáneas ha sido cerrar la puerta, firme e irrevocablemente, a las ilusiones idealistas y sobrenaturalistas que aún impregnan e infectan nuestra perspectiva religiosa" (ibid., p. 709).

18. Cf. Y. Congar, La foi et la théologie, Tournai: Desclée, 1962, pp. 54-71; C. Boff, Teoria do método teológico, op. cit., pp. 249-264; J. L. Segundo, O dogma que liberta: fé, revelação e magistério dogmático, São Paulo: Paulinas, 1991, pp. 181-447. 
ser comprendidas a partir del lugar y de los intereses eclesiales, socioculturales y políticos en que se dan. Eso no niega su verdad ni su autoridad. Por el contrario, ayuda a purificarlas de intereses ideológicos no confesados.

De ahí la necesidad de que la teología se confronte de modo explícito y consecuente con la problemática de su lugar social. Sea explicitando con la ayuda de las ciencias socio-históricas el lugar que ella viene ocupando a lo largo de la historia; sea determinando teológicamente el lugar que ella debe ocupar. Dos tareas distintas, pero que se implican y se remiten mutuamente.

Por un lado, es preciso confrontarse críticamente con la historia de la teología, explicitando el lugar social que ella viene ocupando. Y aquí es fundamental la pregunta del "para qué y para quién" de la teología, es decir, la pregunta sobre "a quién sirve" y "para qué, de hecho, sirve" una determinada teología". No se trata de juzgar el pasado con criterios actuales, porque esa tarea abarca también las más diversas teologías producidas en el presente. Se trata, simplemente, del esfuerzo de identificar el lugar social de las diversas teologías (pasadas y presentes) con las cuales nos confrontamos. Y por una doble razón. Primero, por una cuestión de criticidad y lucidez teórica. Si todas las teologías se producen a partir de y en referencia a un determinado lugar social, es importante y necesario identificar ese lugar social para que esta pueda ser mejor comprendida en sus afirmaciones, en sus objetivos y en sus mediaciones práctico-teóricas. Segundo, por una razón estrictamente teológica, a saber, analizar su legitimidad y sus fundamentos teológicos. En este sentido, la historia de la Iglesia y, concretamente, la historia de la teología no pueden ser reducidas a un elenco de acontecimientos, autores y teorías. Lo teológico de un abordaje de la historia de la Iglesia $\mathrm{y}$, en esta, de la historia de la teología consiste en el análisis e interpretación de esos acontecimientos, autores y teorías, a partir y en vista de la salvación o de la realización del reinado de $\operatorname{Dios}^{20}$. Y para esto no basta identificar el lugar social de una teología cualquiera. Es necesario confrontarlo con el lugar social de la historia de la salvación, tal como se dio en Israel y, particularmente, en la praxis de Jesucristo.

Por otro lado, es necesario determinar el lugar social que la teología debe ocupar. Esa tarea es necesaria, tanto para poder llevar a cabo un abordaje teológico de la historia de la Iglesia y, en esta, de la historia de la teología, como para desarrollar una teología auténticamente cristiana. Pero si la identificación del lugar social de una teología cualquiera se hace, sobre todo, con ayuda de las ciencias socio-históricas y su sospecha ideológica (a quién o a qué intereses

19. I. Ellacuría, "Hacia una fundamentación del método teológico latinoamericano", en Escritos teológicos, t. I, op. cit., pp. 187-218, aquí 214.

20. Cf. I. Ellacuría, "Iglesia y realidad histórica", en Escritos teológicos, t. II, op. cit., pp. 501-515. 
sociales sirve de hecho), la determinación de su lugar es una tarea estrictamente teológica (a quién o a qué intereses debe servir). Hecha a partir de y en referencia a los acontecimientos históricos que funcionan como fundamento, "canon" y criterio tanto para la praxis eclesial como para su momento más propiamente intelectivo, es decir, a la teología misma: la historia de Israel y, en esta, la praxis de Jesucristo. Es a partir de aquí que se puede y se debe justificar y criticar teológicamente el lugar social de una teología cualquiera del pasado o del presente; de un determinado teólogo o del magisterio episcopal. Es a partir de aquí que se evita el relativismo teológico, en la medida en que la discusión del lugar social de la teología es hecha desde un criterio objetivo y, además, históricamente verificable, más allá de todo subjetivismo e idealismo. Y es a partir de aquí que la teología deja de ser un instrumento ideológico de las más diversas formas de opresión y dominación y ejerce de modo consecuente la función profética que le compete en la sociedad, en cuanto momento consciente y reflejo de la salvación o del reinado de Dios en este mundo.

Más que la primera tarea (abordaje histórico), nos interesa ahora la segunda tarea (determinación teológica). Determinar con rigor el lugar social que la teología debe ocupar para que pueda ser auténticamente cristiana, lo que solo es posible en referencia a la realidad que ella busca inteligir y al servicio de la cual debe estar: la realización del reinado de Dios, tal como se dio en la historia de Israel y en la praxis de Jesús de Nazaret, a quien confesamos como el Cristo, Hijo de Dios. Esto es lo que haremos a continuación.

\section{Determinación del lugar social de la teología}

Ya explicado lo que entendemos por lugar social y en qué consiste la problemática del lugar social de la teología, es decir, en qué sentido se puede y se debe hablar de lugar social de la teología, vamos a ocuparnos ahora de la cuestión de la determinación del lugar social que la teología debe ocupar: si en nuestra sociedad hay lugares sociales diferentes e incluso contrarios; si toda teología es hecha a partir de y en referencia a un determinado lugar social, la pregunta ahora es saber si para una teología cristiana, hecha a partir de y en referencia a la praxis de Jesucristo, es indiferente el lugar social que ella ocupa: si es igual ocupar un lugar social u otro (rico o pobre, opresor u oprimido, dominador o dominado, etc.), o si la referencia a la praxis de Jesucristo la obliga a situarse en un determinado lugar aun en oposición a otros lugares. Es esta la problemática de la determinación del lugar social de la teología.

La discusión de la problemática y de la determinación del lugar social de la teología es relativamente reciente y fue desarrollada, sobre todo, en el seno de la teología de la liberación en sus más diversos enfoques y en sus más diversas formulaciones. Desde el principio, los teólogos y las teólogas de la liberación se dieron cuenta tanto de la importancia del lugar social en el quehacer teológico 
como del hecho de que el mundo de los pobres y oprimidos constituye el lugar social fundamental de la revelación, de la fe y de la teología cristiana. Para el primer aspecto (importancia del lugar teológico en el quehacer teológico), fue decisivo el contacto y el diálogo con las ciencias sociales, históricas, antropológicas, hermenéuticas, etc. Ya el segundo aspecto (mundo de los pobres y oprimidos como lugar social de la teología) se dio fundamentalmente a través de la teología bíblica y de su función canónica en el conjunto de la teología cristiana — “debe ser como el alma de toda la teología" (Optatam totius 16)_. Es en este contexto que se va a hacer común hablar del lugar social de la teología, formulado de diversas maneras: pobre, mundo de los pobres y oprimidos, pueblos dominados, clases explotadas, razas despreciadas, mayorías populares, pueblos crucificados, etcétera ${ }^{21}$.

Es importante explicitar aquí, sin mayores desarrollos, las razones teológicas que han llevado a los teólogos y a las teólogas a afirmar que el lugar social de la teología es el mundo de los pobres y oprimidos o, dicho de otra forma, que el mundo de los pobres y oprimidos es el lugar teológico fundamental.

a. Ante todo, por ser el lugar de la revelación y de la fe. Si hay algo que no se puede negar ni ocultar en la Sagrada Escritura es la centralidad de los pobres y oprimidos en la historia de la salvación. Dios aparece (revelación) como Go`el que rescata a sus parientes de la esclavitud, como Rey que hace justicia a los pobres y oprimidos, como Padre que cuida de sus hijos y los socorre en sus necesidades. Y la relación con él (fe) pasa siempre por la observancia y defensa del derecho del pobre y del oprimido, por la cercanía hacia el caído en la orilla del camino. Todas las imágenes o metáforas que la Escritura usa para hablar de la acción e interacción entre Dios y su pueblo (Go`el, Rey, Padre, etc.) revelan la centralidad de los pobres y oprimidos, quienes están recogidos y expresados en la fórmula "pobre-huérfano-viuda-extranjero". Y tanto en las escrituras hebreas

21. Cf. L. Boff, Jesus Cristo libertador: ensaio de cristologia crítica para o nosso tempo, Petrópolis: Vozes, 1991, pp. 15-37; A fé na periferia do mundo, Petrópolis: Vozes, 1991; Do lugar do pobre, Petrópolis: Vozes, 1997; C. Boff, Teologia e prática, op. cit., pp. 281-303; I. Ellacuría, "Los pobres, 'lugar teológico' en América Latina”, en Escritos teológicos, t. I, op. cit., pp. 139-161; "La Iglesia que nace del pueblo por el Espíritu", op. cit.; "El auténtico lugar social de la Iglesia", en Escritos teológicos, t. II, op. cit., pp. 439-451; J. Sobrino, Jesus, O Libertador: a história de Jesus de Nazaré, Petrópolis: Vozes, 1996, pp. 42-61; L. C. Susin, "O privilégio e o perigo do "lugar teológico' dos pobres na igreja”, en J. M. Vigil (comp.), Descer da cruz os pobres: cristologia da libertação, São Paulo: Paulinas, 2007, pp. 322-329; "Os pobres como 'lugar teológico': uma questão hermenêutica crucial de nosso tempo", en Sociedade de Teologia e Ciências da Religião (SOTER) (comp.), Deus e vida: desafios, alternativas e o futuro da América Latina e do Caribe, São Paulo: Paulinas, pp. 151-180; F. Aquino Júnior, A teologia como intelecção do reinado de Deus, op. cit., pp. 265-318; “Sobre o conceito 'lugar teológico"”, REB 278 (2010), pp. 451-453. 
(AT) como en las escrituras cristianas (NT). Joachim Jeremias, exégeta alemán, insistió mucho en que el "trazo decisivo" del reinado de Dios, centro y resumen de la predicación de Jesús, consiste en la "oferta de la salvación hecha por Jesús a los pobres" 22 - "únicamente, los pobres", llega a afirmar ${ }^{23}-$. De modo que la salvación de los pobres y oprimidos constituye el corazón de la historia de Dios con su pueblo.

Ahora bien, si la teología consiste en la intelección del reinado de Dios ${ }^{24}$ y si este está relacionado ante todo y por encima de todo con la salvación de los pobres y oprimidos, el quehacer teológico es inseparable del mundo de los pobres y oprimidos. Y no solo en el sentido de que este se convierta en "objeto" o asunto de la teología, sino, sobre todo, en cuanto lugar privilegiado de intelección de la historia de la salvación. Es un principio teórico-epistemológico básico: el lugar fundamental de la salvación (revelación/fe) es también el lugar fundamental de su intelección (teología), es decir, el lugar donde esta se deja aprehender más y mejor ${ }^{25}$.

b. Segundo, porque más allá de ser el lugar privilegiado de acceso/aprehensión de la historia de la salvación o del reinado de Dios, los pobres y oprimidos son los destinatarios privilegiados de la salvación al servicio de los cuales está la propia teología, en cuanto su momento intelectivo por excelencia. Por más universal que sea la salvación (ofrecida a todos), su realización histórica siempre es parcial (comienza y pasa necesariamente por los últimos). Dios quiere salvar a todos y lo hace comenzando por los últimos y a través de ellos. Esa es la dinámica de la salvación tal como aparece en la Sagrada Escritura - para escándalo de muchos ( $c f$. Lc 4, 16-21; 17, 18-23; 10, 25-37; Mt 25, 31-46)-. Y eso no es indiferente al quehacer teológico. En cuanto intelección del reinado de Dios que se constituye como "oferta de la salvación" a los pobres y oprimidos, la teología también está al servicio de los pobres y oprimidos, y este "estar al servicio de" determina enormemente su dinamismo. Por un lado, ella trata del reinado de Dios que se destina a los pobres y oprimidos (asunto de la teología). Por otro lado, está al

22. J. Jeremias, Teologia do Novo Testamento, São Paulo: Hagnos, 2008, p. 176.

23. Ibid., p. 187.

24. $C f$. F. Aquino Júnior, "O reinado de Deus como assunto da teologia cristã”, REB 81 (2011), pp. 47-68.

25. Cf. I. Ellacuría, "Los pobres, 'lugar teológico' en América Latina”, op. cit., p. 151. Esto no niega, en hipótesis alguna, la especificidad y autonomía relativa de la teología en "relación" a la revelación y a la fe. Ella tiene "leyes propias y métodos propios [...] que son insustituibles". Pero "no hay que hacerse ilusiones sobre el ámbito y el ejercicio de esa autonomía, pues el teólogo y su hacer dependen enormemente del horizonte en que se mueven y de la praxis a que se orienta". Mucho más de lo que se piensa (ibid., pp. 151 y s.). 
servicio de ese mismo reinado, como su momento consciente y reflexivo por excelencia (actividad intelectiva).

Es una cuestión metodológica fundamental: la meta que se quiere alcanzar determina en gran medida el camino que se debe recorrer. No se llega a cualquier lugar por cualquier camino ni se puede determinar el camino a ser recorrido independientemente del lugar a donde se quiere llegar. En otras palabras, la orientación fundamental de la teología (¿para quién?, ¿en función de quién?) es mucho más decisiva y determinante del quehacer teológico de lo que se piensa. Y tanto en lo que dice respecto a la búsqueda y construcción de mediaciones prácticas como en lo que dice respecto a su interacción con los más diversos procesos históricos ${ }^{26}$.

c. Tercero, por ser el lugar más adecuado de historización y verificación de la teología. En la medida en que la teología es intelección de una realidad prácticosalvífica (reinado de Dios), debe encontrar siempre alguna forma, más o menos directa, de historización y verificación: "Una teoría teológica que no sea verificable en la praxis teologal, carece al menos de una dimensión esencial suya que es la historicidad" y, además de "des-potenciar la praxis teologal requerida", termina dejando de ser "un intellectus fidei para ser un estudio de inoperatividades" 27. Además, en la medida en que esa praxis salvífica se destina antes que nada y por encima de todo a los pobres y oprimidos y, así, está intrínsecamente referida a ellos, encuentra ahí su lugar fundamental de historización: el lugar donde ella debe ser probada y donde su verdad debe ser comprobada o verificada. De este modo, el discurso de Jesús sobre Dios como Rey que hace justicia a los pobres y como Abba compasivo y misericordioso se torna realidad y se hace verdad (se verifica) en su praxis junto a los pobres y oprimidos de su tiempo.

Es más un aspecto del proceso de conocimiento en general y del conocimiento teológico en particular. En cuanto teoría del reinado de Dios, la teología

26. Toda teología tiene repercusiones sociales. Quiera o no quiera, consciente o inconscientemente, toda teología acaba legitimando y, así, sirviendo a determinados intereses sociales. Por eso mismo, es muy importante determinar su orientación y sus destinatarios fundamentales (su para quién) para que no termine sirviendo a intereses contrarios a los que, en principio, se propone servir. Una teología que se pone explícita y conscientemente al servicio de la salvación de los pobres y oprimidos, como debe ser la teología cristiana, es mucho más sensible a las diversas formas de dominación y está mucho más preocupada y comprometida con la búsqueda de las mediaciones prácticas y teóricas para la salvación de los pobres y oprimidos de este mundo. Esa orientación fundamental se hace, así, determinante de su dinamismo histórico: mediaciones teóricas y prácticas, interacción en los procesos sociales y políticos, etc.

27. I. Ellacuría, "Relación teoría y praxis en la teología de la liberación", en Escritos teológicos, t. I, op. cit., pp. 235-245, aquí 241 y s. 
parte del acontecimiento histórico de la salvación de los pobres y oprimidos (lugar de su aprehensión) y revela o realiza su verdad en el mismo proceso histórico de la salvación de los pobres y oprimidos (lugar de verificación). La historia de la salvación de los pobres y oprimidos se convierte, así, tanto en el lugar de aprehensión de la salvación como en el lugar de comprobación o verificación de una teoría de la salvación.

d. Cuarto, por constituir un principio y un criterio fundamental de desideologización de la teología. Conforme ya advertimos, el discurso teológico está mucho más propenso a "tergiversaciones y manipulaciones no siempre conscientes" que otros discursos: sea por el carácter "aparentemente" inverificable de muchas de sus afirmaciones ${ }^{28}$, sea por la pretensión de universalidad, objetividad y cientificidad de su discurso. De ahí que sea tan importante el problema del "para dónde" apunta/conduce o "a quién" sirve una determinada teología. En cierto sentido hasta se puede decir que el "para dónde" o el "para quién" de una teología revela la verdad de su "a partir de dónde" y, así, se constituye en criterio de la propia verdad de la teología: si esta pretende ser la intelección del reinado de Dios, cuyos destinatarios privilegiados son los pobres y oprimidos, pero, en la práctica, está al servicio o favorece mucho más a los ricos y opresores, es señal o indicio muy fuerte de que la realidad inteligida no fue realmente o propiamente el reinado de Dios, tal como aparece en la Escritura, o, por lo menos, que Dios fue instrumentalizado o ideologizado en función de otros intereses.

Juan Luis Segundo insistió mucho en la importancia de la "sospecha ideológica" como momento constitutivo y fundamental del quehacer teológico ${ }^{29}$. La propia palabra de Dios, dice Segundo, "pretende en todo instante recordar al teólogo que su interpretación de la revelación, para entenderla y practicarla, se puede desviar y comenzar a servir a los fines de la explotación del hombre por el hombre" ${ }^{" 30}$. Por eso mismo, es fundamental ver si cualquier teología está al servicio de la salvación de los pobres y oprimidos o si contribuye, por omisión o por comisión, con su explotación y dominación. Y, aquí, el mundo de los pobres y oprimidos se constituye en principio y criterio fundamental de legitimidad y/o de desideologización de la teología.

En síntesis, el mundo de los pobres y oprimidos es el lugar fundamental de la teología cristiana en cuanto lugar privilegiado de acceso real al reinado de Dios

28. I. Ellacuría, "La teología como momento ideológico de la praxis eclesial", op. cit., p. 165.

29. Cf. J. L. Segundo, Libertação da teologia, São Paulo: Loyola, 1978, pp. 9-12; "Críticas y autocríticas de la teología de la liberación", en J. Comblin, J. I. González Faus y J. Sobrino, Cambio social y pensamiento cristiano en América Latina, Madrid: Trotta, 1993, pp. 215-236, aquí 232-236.

30. J. L. Segundo, "Críticas y autocríticas", op. cit., p. 234. 
(su asunto u objeto); en cuanto ofrece una orientación fundamental al quehacer teológico (su para quién); en cuanto lugar más adecuado de historización y verificación de la teología (su verdad); y en cuanto principio y criterio de desideologización de la teología (su prueba de fuego).

Conviene, finalmente, advertir que la expresión "lugar teológico" es tomada aquí en un sentido bien diferente del que tiene en Tomás de Aquino ${ }^{31}$, en Melchor Cano $^{32}$ y, a partir de ellos, en el magisterio de la Iglesia y en la mayoría de teólogos: "fuentes" o "domicilios" de argumentos teológicos.

Es verdad que esa mutación semántica en la expresión "lugar teológico" no se da apenas en el sentido de lugar social como lo desarrollamos aquí. Ni siquiera comienza por ahí. Desde el Concilio Vaticano II viene siendo utilizada, desde perspectivas diferentes, en un sentido bien distinto del que esta expresión tiene en la tradición teológica. Se ha hablado muchas veces del mundo, de la Iglesia, de la liturgia, de la vida de santidad, etc., y también, está claro, del pobre como lugar teológico. Y, normalmente, en referencia a la obra de Melchor Cano sobre los lugares teológicos, como si fuese una ampliación y/o actualización de la misma ${ }^{33}$. Y aquí está el problema y una de las razones de ciertas incomprensiones y hasta injusticias. Hablamos de una de las razones porque, curiosamente, las reacciones, resistencias y conflictos se dan prácticamente con relación a la afirmación del pobre como lugar teológico, aunque, en la perspectiva de Cano, como advierte Max Seckler, tampoco se puede hablar de la actualidad, de la Iglesia o de la liturgia como lugar teológico ${ }^{34}$.

Ciertamente se puede ampliar el número de las "fuentes" o de los "domicilios" de los argumentos teológicos. El propio Cano recuerda, al identificar y/o determinar los diez lugares teológicos, que algunos reducirían y otros aumentarían ese número. Pero no da mucha relevancia a esa cuestión. Lo importante, para

31. Cf. T. Aquino, Suma teológica, t. I, São Paulo: Loyola, 2001, I, q.1, a.8, ad 2.

32. M. Cano, De locis theologicis, Madrid: BAC, 2006.

33. Cf. E. Schillebeeckx, Revelação e teologia, São Paulo: Paulinas, 1968, pp. 189-192; J. Wicks, "Lugares teológicos", en R. Latourelle y R. Fisichella (dir.), Dicionário de Teologia Fundamental, Petrópolis/Aparecida: Vozes/Santuário, 1994, pp. 551-552; Introdução ao método teológico, São Paulo: Loyola, 1999, pp. 18-22; F. Taborda, O memorial da páscoa do Senhor, São Paulo: Loyola, 2009, pp. 31-37; L. C. Susin, "O privilégio e o perigo do 'lugar teológico' dos pobres na igreja", op. cit.; "Os pobres como "lugar teológico", op. cit.

34. $C f$. M. Seckler, "Die ekklesiologische Bedeutung des Systems der 'loci theologici': Erkenntnistheoretische Katholizität und strukturale Weisheit”, en W. Baier (ed.) Weisheit Gottes, Weisheit der Welt: Festschrift für Joseph Kardinal Ratzinger zum 60. Geburtstag, t. I, St. Ottilien: EOS Verlag, 1987, pp. 37-65, aquí 44, nota 12. 
su propósito, es que "no se enumere ningún lugar superfluo ni se omita ningún lugar necesario" 35 .

Y ciertamente también se puede dar a la expresión "lugar teológico" un sentido diferente del que tiene en la obra de Cano, es decir, se puede hablar de lugar teológico como lugar eclesial, como acto litúrgico, como lugar social, etc. La historia de la teología no carece de ejemplos de mutación semántica, comenzando por el término teología. Las expresiones pueden adquirir un nuevo sentido o cambiar de sentido. Esto no es problema.

Pero es necesario dejar claro en qué sentido se usa la expresión, sobre todo cuando se trata de una expresión polisémica, como lo es "lugar teológico". En Melchor Cano significa los lugares textuales - "fuentes" o "domicilios"- donde se pueden encontrar argumentos para el discurso teológico. Una especie de "área de documentación", en la expresión de Wicks ${ }^{36}$. En la perspectiva de Cano no tiene sentido hablar de la vida eclesial, de la acción litúrgica o del mundo de los pobres y oprimidos como lugar teológico, lo que no significa que la expresión no pueda ser tomada en ese sentido. En todo caso, es importante tener presente esos diferentes sentidos y dejar claro en qué sentido está siendo usada. Y tanto por precisión teórica como para evitar incomprensiones y conflictos innecesarios. Es lo que hace, por ejemplo, Ignacio Ellacuría, al distinguir entre "fuentes" de la teología (lugar teológico, en el sentido de Melchor Cano) y "lugar" social de la teología (lugar teológico, en el sentido de la teología de la liberación), y al mostrar cómo las fuentes son leídas e interpretadas siempre a partir de un determinado lugar social ${ }^{37}$. De esta forma, deja claro el sentido que da a la expresión lugar teológico (lugar social), distinguiéndola del sentido clásico de esa expresión (fuente o domicilio de argumento) y mostrando, incluso, su articulación con él.

\section{A modo de conclusión}

Que toda teología se hace a partir de un lugar social concreto y termina sirviendo a determinados intereses sociales es un hecho fácilmente constatable. Que deba ser hecha a partir del lugar de los pobres y oprimidos y que esté al servicio de su liberación es una exigencia que brota de la dinámica misma de la revelación y de la fe cristiana. No es una cuestión secundaria u opcional, ni siquiera es una cuestión meramente pastoral, sino una cuestión que hace referencia a la identidad cristiana de la teología. Es tanto una cuestión de ortopraxis como una cuestión de ortodoxia. Finalmente, como recordaba Juan Pablo II en su Carta apostólica Novo millennio ineunte:

35. M. Cano, De locis theologicis, op. cit., p. 9.

36. J. Wicks, "Lugares teológicos", op. cit., p. 20.

37. Cf. I. Ellacuría, "Los pobres, 'lugar teológico’ en América Latina”, op. cit., pp. 152 y s. 
Si verdaderamente hemos partido de la contemplación de Cristo, tenemos que saberlo descubrir sobre todo en el rostro de aquellos con los que él mismo ha querido identificarse: "He tenido hambre y me habéis dado de comer, he tenido sed y me habéis dado que beber; fui forastero y me habéis hospedado; desnudo y me habéis vestido, enfermo y me habéis visitado, encarcelado y habéis venido a verme" (Mt 25, 35-36). Esta página no es una simple invitación a la caridad: es una página de cristología, que ilumina el misterio de Cristo. Sobre esta página, la Iglesia comprueba su fidelidad como Esposa de Cristo. (NMI 49.)

Y lo que vale para la praxis eclesial en general, vale, mutatis mutandis, para su momento intelectivo por excelencia que es la teología.

Está claro que el lugar social del pobre y oprimido no produce automáticamente una teoría teológica ni genera su calidad teórica, pero le ofrece un acceso privilegiado a su "objeto", una orientación fundamental a su quehacer, el lugar más adecuado de su historización y verificación, y un principio y criterio histórico de su desideologización. Y, así, se constituye en un momento fundamental y determinante del método teológico. 